\title{
Los imaginarios de los actores sociales del Pueblo Mágico de Ixtapan de la Sal, México
}

\author{
Alejandra Díaz Castañeda* Maribel Osorio García**
}

Universidad Autónoma del Estado de México (México)

\begin{abstract}
Resumen: La producción simbólica de un lugar turístico implica que el espacio ha sido apropiado e intervenido por agentes políticos y económicos para proyectar imágenes y signos que contribuyan a la reproducción de los grupos sociales, pero transformando las relaciones sociales y las experiencias de lugar tanto de quienes lo consumen como de quienes lo viven cotidianamente. De lo anterior, la importancia del análisis y comparación de los imaginarios espaciales de los diferentes actores sociales que intervienen en el fenómeno turístico mediante las subjetividades. La condición de la posmodernidad de Harvey (1990), las categorías de análisis de lugar y no-lugar de Augé (1992) y entre-lugar turístico de Castrogiovanni (2007) permitieron la comprensión de la fragmentación simbólica del lugar para los pobladores, así como los cambios en las experiencias de los turistas.
\end{abstract}

Palabras Clave: Imaginarios; Actores sociales; Pueblo mágico; Turismo; Producción social

The imaginaries of social actors of the Magical Village of Ixtapan de la Sal, Mexico

Abstract: The symbolic production of a tourist place implies that the space has been appropriated and intervened upon by political and economic agents to project images and signs that contribute to the reproduction of social groups, but transforming the social relations and experiences of the place both for those who consume it and for those who live there at least on a daily basis. Hence it is important to analyse and compare the subjective spatial world visions of the different social agents intervening in tourism. To this end, we have used postmodernity as defined by Harvey (1990), the categories of place and non-place of Augé (1992) and the "between-place" of tourism as defined by Castrogiovanni (2007) to understand the symbolic fragmentation of place for the residents as contrasted with the experiences of the tourists.

Keywords: World vision; Social agents; Magic village; Tourism; Social production

\section{Introducción}

El turismo se concibe como la producción de espacios que son consumidos por medio de las experiencias (López Santillán y Marín Guardado, 2010). También es un producto social, dada la intervención de diferentes actores sociales para llevar a cabo la práctica turística en un tiempo y espacio determinado (Antón Clavé, 1998).

De manera que, el turismo ha conquistado el tiempo y el espacio. El primero, mediante la democratización del ocio, el segundo a través del reconocimiento de una porción del lugar que proyecte la imagen e identidad colectiva por parte de las instituciones públicas y/o privadas, para apropiarlo, comercializarlo y promocionarlo, es decir, convertirlo en un lugar turístico que permita el desarrollo y/o la concentración del capital (Antón Clavé, 1998; Barbini, 2005; Lagunas Arias, 2006). Mientras que los turistas por medio de su localización y consumo in situ, les permite alejarse de su cotidianeidad (Antón Clavé, 1998).

Por lo tanto, la urbanización turística es distintiva, de acuerdo con los símbolos urbanos que lo público y/o privado deseen incentivar para atraer turistas. Es decir, en la relación hombre-espacio de un destino turístico, el espacio es objetivo, pero el valor tanto del espacio como de los objetos naturales y/o culturales que se encuentran en él son subjetivos. El valor subjetivo del espacio varía de acuerdo

* Universidad Autónoma del Estado de México (México); E-mail: calabacitale@gmail.com; https://orcid.org/0000-0001-8488-1789
*niversidad Autónoma del Estado de México (México); E-mail: maribelosorio2@gmail.com; https://orcid.org/0000-0002-3336-6231 
con los intereses, motivaciones, etc., de los actores sociales que intervienen desde la producción hasta el consumo del lugar turístico (Antón Clavé, 1998; Castrogiovanni, 2007).

Entonces, la producción de un lugar turístico implica cuestiones simbólicas, dado que el espacio ha sido ocupado y apropiado de acuerdo con las imágenes y signos que sirven para la producción y reproducción de los grupos sociales, pero tal configuración espacial, transforma las relaciones sociales, las prácticas materiales, es decir, produce otras subjetividades en quienes lo consumen; "los espacios son pensados, interpretados y decodificados, según diversos actores" (Lagunas Arias, 2006:123).

Las imágenes, las valorizaciones, las prácticas, las motivaciones, los comportamientos, la espacialidad, los sentimientos, etc. del entorno turístico se traducen en discursos de las vivencias y experiencias de lugar, lo que nos aproxima al análisis de los imaginarios de los diferentes actores sociales que intervienen en la producción y consumo de los lugares turísticos (Bertoncello, 2012; Hiernaux, 2012; Lindón, 2012). Los imaginarios turísticos son los significados asignados tanto a las prácticas como a los lugares turísticos, lo que permite comprender los procesos, la expansión, el uso y la apropiación del espacio (Lagunas Arias, 2006; Lindón, 2012).

Tal dimensión subjetiva, proveniente de la teoría social contemporánea se ha ido incorporando a la geografía del turismo (giro cultural) para reflexionar sobre el "vivir, sentir y actuar cotidiano" (Pinassi, 2015:138). De manera que, se han analizado los imaginarios de los turistas, de la población local, etc. y la relación que cada actor social tiene con el espacio (Barbini, 2005).

El estudio de los imaginarios de los turistas permite entender la realidad por medio de su experiencia para valorar sus prácticas socioespaciales, los impactos económicos y socioculturales de las sociedades receptoras (Antón Clavé, 1998; Hiernaux y González, 2014; López Santillán y Marín Guardado, 2010; Moscoso, 2013). También, sus valoraciones, sus motivaciones, etc. permiten generar tipologías mediante metodologías cuantitativas (López-Guzmán, Pérez Gálvez y Muñoz-Fernández, 2018).

Los imaginarios del espacio implican el reconocimiento y la comprensión de los significados de lugares cargados de sentidos, códigos y prácticas de acuerdo con las experiencias y los valores que los actores sociales les asignan (Venturini, 1999). Tal concepto implica vivir y construir el lugar turístico por los diferentes actores sociales, desde una perspectiva cualitativa (subjetiva, afectiva, interpretativa). Por ejemplo, las subjetividades de los pobladores señalan los cambios físicos y simbólicos que ha sufrido un destino turístico (Barrera, 2016), mientras que un prestador turístico da a conocer la confrontación de intereses y toma de decisiones (Moscoso, 2013).

En el ámbito de los imaginarios urbanos, ha surgido una fructífera veta de investigación en México en las localidades catalogadas como "Pueblos Mágicos", ciudades que han obtenido tal denominación por tener algún atributo simbólico o cultural con aprovechamiento turístico (Secretaría de Turismo, 2006), que, contradictoriamente, pretenden expresar el imaginario de lo "rural" mexicano (Méndez y Rodríguez, 2013). Varios estudios han incursionado en reconocer las transformaciones materiales y simbólicas en estas localidades (López, Valverde, Fernández y Figueroa, 2015; López, Valverde y Figueroa, 2015, 2017 y 2018), pero pocos han profundizado en comparar los imaginarios de los distintos actores sobre el espacio simbólico del destino. Por ello, el propósito de este trabajo de investigación es el análisis de los imaginarios espaciales del Pueblo Mágico Ixtapan de la Sal, a partir de las subjetividades de las autoridades y empresarios que intervienen en la producción del destino, de los turistas que lo consumen y de la población local que viven las transformaciones.

El texto se estructura de un marco teórico, del contexto general del Pueblo Mágico de Ixtapan de la Sal, la metodología cualitativa, los resultados y discusión de la investigación, reflexiones finales y las referencias bibliográficas.

\section{Marco teórico}

Para el estudio de los imaginarios espaciales de los diferentes actores sociales que intervienen en la producción y consumo del lugar turístico de Ixtapan de la Sal se retoman algunos de los planteamientos sobre la posmodernidad de Harvey (1990), las categorías de análisis lugar y no-lugar de Marc Augé (1992), así como de Entre-Lugar turístico de Castrogiovanni (2007).

\subsection{La condición de la posmodernidad}

Para Harvey (1990), la racionalidad instrumental en su afán de romper con la tradición y liberar al hombre de las necesidades y de las catástrofes naturales, usó principios morales, políticos, económicos y estéticos para emancipar la vida social y cultural e instaurar el desarrollo capitalista. 
Cada etapa del sistema capitalista determina prácticas materiales y procesos de producción social que modifican las cualidades y significados del tiempo y del espacio, influyendo en el ordenamiento de la vida diaria tanto en la modernidad como en la posmodernidad. En la primera, se promueven nuevas condiciones de producción, de circulación de mercancías y de consumo que modifican la experiencia urbana; cuya exacerbación se da en la posmodernidad.

De manera que, en las sociedades capitalistas avanzadas se reflejan cambios en las prácticas, las actitudes, las experiencias en el tiempo y el espacio relacionadas con la transición del fordismo al posfordismo, generando una crisis y contradicciones en las representaciones de las formas culturales. De hecho, cobra importancia el significante, el presente material desvinculado en el tiempo, la búsqueda de la seguridad e identidad colectiva, el estatus, la producción de necesidades etc., debido a la compresión espacio-temporal dadas las posibilidades multimediáticas y así asegurar la rentabilidad, pero enmascarando las relaciones sociales de producción.

De lo anterior, Harvey (1990) coloca a la posmodernidad como una condición histórico-geográfica determinada en la que se evoca a la industrialización, el Estado Benefactor, el neoliberalismo y la globalización.

En la industrialización, la modernización técnica facilita el sistema de producción fordista que garantice el consumo masivo de productos estandarizados a nivel mundial. El Estado Benefactor consiste en políticas fiscales y monetarias destinadas a la inversión pública, además, de la instauración de derechos sociales a los trabajadores para acceder a bienes y servicios (Pérez Correa y Farah Quijano, 2002; López, 2004; Schenkel y Almeida García, 2015; Harvey, 1990). En el turismo se refleja en la masividad de destinos de sol y playa y balnearios, y en la dependencia hacia los turistas extranjeros (Barbini, Roldán, Cacciutto y Cruz, 2009; Orozco Alvarado y Núñez Martínez, 2013).

El neoliberalismo proclama la apertura comercial internacional, la libre competencia, así como el sistema de producción y trabajo flexible, dando como consecuencias: la descentralización y la fragmentación espacial, la precarización laboral, la escenificación del espacio para su mercantilización y el consumo de capital simbólico (Pérez Correa y Farah Quijano, 2002; Orozco Alvarado y Núñez Martínez, 2013; Harvey, 1990). La expansión global del sistema capitalista mediante la intercomunicación mundial permite la transnacionalidad de la información y el consumo, reduciendo el tiempo y el espacio, por lo tanto, integrando zonas alejadas a la economía del mercado de servicios (López, 2004; César Dachary, 2015; César Dachary y Arnaiz Burne, 2004). Surge un turismo segmentado y especializado en lugares desconocidos, de acuerdo con el tiempo y necesidades específicas de los turistas (Bringas Rábano y Ojeda Revah, 2000).

Por lo que, para la comprensión del control social de la vida, el tiempo y el espacio en la posmodernidad, y con ello, los impactos y significados en la producción y consumo del espacio, Harvey (1990), se basa en la trialéctica de Lefebvre (2013). La trialéctca de Lefebvre se compone de: las prácticas materiales, las representaciones del espacio y los espacios de representación. Es decir, el espacio se concibe y se produce de acuerdo con una representación e ideología determinada, para que, mediante su consumo, se conforme una experiencia. Sin embargo, de acuerdo con los fines de este artículo, la presente investigación se concentra en los espacios de representación de las autoridades, los empresarios, los turistas y la población local.

Los espacios de representación "son invenciones mentales...que imaginan nuevos sentidos o nuevas posibilidades de las prácticas espaciales" (Harvey, 1990:244). Los imaginarios sirven para leer la historia de las prácticas espaciales, por lo que se cruzan con cuatro variables: accesibilidad y distanciamiento tanto en la interacción humana como espacial, apropiación y uso del espacio, dominación y control del espacio y, la producción del espacio (Tabla 1).

Tabla 1: Variables de análisis de los espacios de representación.

\begin{tabular}{|l|l|l|l|l|}
\hline $\begin{array}{c}\text { Variables } \\
\text { Dimensión }\end{array}$ & $\begin{array}{c}\text { Accesibilidad y } \\
\text { distanciamiento }\end{array}$ & $\begin{array}{c}\text { Apropiación y } \\
\text { uso del espacio }\end{array}$ & $\begin{array}{c}\text { Dominio y control del } \\
\text { espacio }\end{array}$ & $\begin{array}{c}\text { Producción } \\
\text { del espacio }\end{array}$ \\
\hline $\begin{array}{l}\text { Espacios de } \\
\text { representación }\end{array}$ & $\begin{array}{l}\text { Atracción/ } \\
\text { rechazo }\end{array}$ & $\begin{array}{l}\text { Familiaridad; } \\
\text { lugares abiertos; } \\
\text { lugares de } \\
\text { espectáculo }\end{array}$ & $\begin{array}{l}\text { No familiaridad; } \\
\text { propiedad y posesión; } \\
\text { monumentalismo y } \\
\text { espacios de ritual } \\
\text { construidos; barreras } \\
\text { simbólicas }\end{array}$ & $\begin{array}{l}\text { Proyectos } \\
\text { utópicos; } \\
\text { mitologías } \\
\text { del espacio; } \\
\text { espacios del } \\
\text { deseo }\end{array}$ \\
\hline
\end{tabular}

Fuente: Elaboración propia, de acuerdo con David Harvey (1990). 
La atracción/rechazo indican si los agentes sociales y económicos tienen acceso o no al destino y a los atractivos turísticos; la apropiación permite la familiaridad con la que hacen uso del espacio turístico. La dominación y control del espacio mediante la no familiaridad, así como los cambios espaciales y económicos, mismos que refuerzan la imagen espacial por medio de la tradición o la modificación de la representación. La producción del espacio se manifiesta en los proyectos imaginados y/o utópicos de los actores sociales que planifican el espacio.

La dimensión de los espacios de representación permite analizar el espacio social como producto y productor de la ideología capitalista. Es producto al responder a los imaginarios y necesidades funcionales de determinadas clases hegemónicas que organizan, alteran y especializan el espacio. Es productor al implantar una ideología dominante que regula la vida social, el tiempo y el espacio de los usuarios, con ello, modificado los usos y significados del espacio.

Si bien el pensamiento de Harvey (1990) ha sido criticado por tener una postura radical, de reducción al análisis de clase y de prevalecer la cuestión espacial (Gintrac, 2013), sus aportaciones dan cuenta sobre como los nuevos modelos productivos y financieros implican un cambio de modelo productivo y social a escala global y local, además, permiten entender la estructura urbana en términos de distribución de riqueza, poder y dominación (Casellas, 2008; Gintrac, 2013).

\subsection{El lugar, el no-lugar y el entre-lugar turístico}

El lugar es un espacio habitado por gente que se relaciona y convive para crear una identidad y una cultura a través del tiempo, por lo que tiene un sentido histórico y una delimitación espacial y social. Por ende, los lugares se caracterizan por ser "identificatorios, relacionales e históricos" (Augé, 1992:21).

El no lugar son las "instalaciones necesarias para la circulación acelerada de personas y bienes" (Augé, 1992:22). Son puntos de tránsito ocupados provisionalmente, por lo que hay una relación contractual, además, la mediación entre individuos-espacio se da por medio de textos (imagen del espacio). Es decir, no crea identidades ni relaciones.

El pensamiento de Augé (1992) proporciona categorías para el análisis del espacio geográfico en la sociedad global (Maldonado Garay, 2010), pero para Korstanje (2007) el hecho de que no se base en casos empíricos ha producido que omita algunas consideraciones, tales como: el rol social en los no lugares, las interacciones fragmentadas, las relaciones contractuales aparecen tanto en los lugares como en los no-lugares; la cooperación y el conflicto de un no lugar lo convierten en lugar; lo cercano y lo lejano dependen de las subjetividades.

Entonces, el lugar y el no lugar nunca existen bajo formas puras, sino que se resignifican de acuerdo con el sentido, las experiencias, las relaciones entre los individuos y de estos con el espacio. Lo anterior, ha permitido la aparición de otros conceptos para explicar las relaciones entre los individuos y estos con su entorno, como el tercer espacio o Entre-Lugar turístico de Castrogiovanni (2007).

El tercer espacio "es un espacio construido entre los Lugares...Esta construcción se produce en la relación entre los objetos y los sujetos con los turistas, sujetos nómadas que durante su permanencia en el Lugar producen acciones colonizadoras sobre los sujetos, interactuando en la cultura, los valores, las formas, sobre y con los objetos existentes" (Catrogiovanni, 2007:17). Es decir, el Entre-Lugar se conforma de acuerdo con la experiencia entre los sujetos (espacialidad) y éstos en el espacio en un tiempo determinado (temporalidad).

De manera que, el Entre-Lugar turístico es un espacio multiterritorializado, creado para satisfacer las necesidades del visitante, que con sus comportamientos y sentimientos favorece la interculturalidad mediante el lenguaje verbal y no verbal (Castrogiovanni, 2007).

\section{Pueblo Mágico de Ixtapan de la Sal}

Ixtapan de la Sal es un municipio del Estado de México ubicado al sur de la Ciudad de Toluca (Figura 1). Cuenta con una Cabecera Municipal, que lleva el mismo nombre, 41 delegaciones y 1 subdelegación. Tiene un total de 35, 552 habitantes (Gobierno del Estado de México, 2016-2018). Es un destino turístico basado en la explotación comercial de 4 de los 10 borbollones de agua termal. Su clasificación climática es ACwg, es decir, semicálido y subhúmedo con lluvias en verano (Gobierno Municipal, 2013-2015).

Ixtapan de la Sal era un pueblo de paso para los arrieros que conducían metal desde Real de Minas hasta Tenango del Valle, quienes junto con la eventual población flotante aprovechaban el agua termal al aire libre del "Bañito" (Cronista Municipal, 2018). En 1930 se edifica el "Balneario" del Sr. Arturo San Román Chávez debido a la obtención de la concesión de las aguas termales "Baños San Gaspar", generando un impulso turístico, debido a la llegada de turistas internacionales. Además, se inaugura 
la carretera Toluca-Ixtapan de la Sal, se construyeron diferentes servicios de alojamiento de distintas categorías principalmente en la Cabecera Municipal, por lo tanto, produciendo una configuración en la imagen urbana con fines turísticos (Cruz Jiménez, Cadena-Inostroza y Zizumbo-Villarreal, 2011; Gobierno del Estado de México, 2016-2018).

Figura 1: Ubicación geográfica de Ixtapan de la Sal.
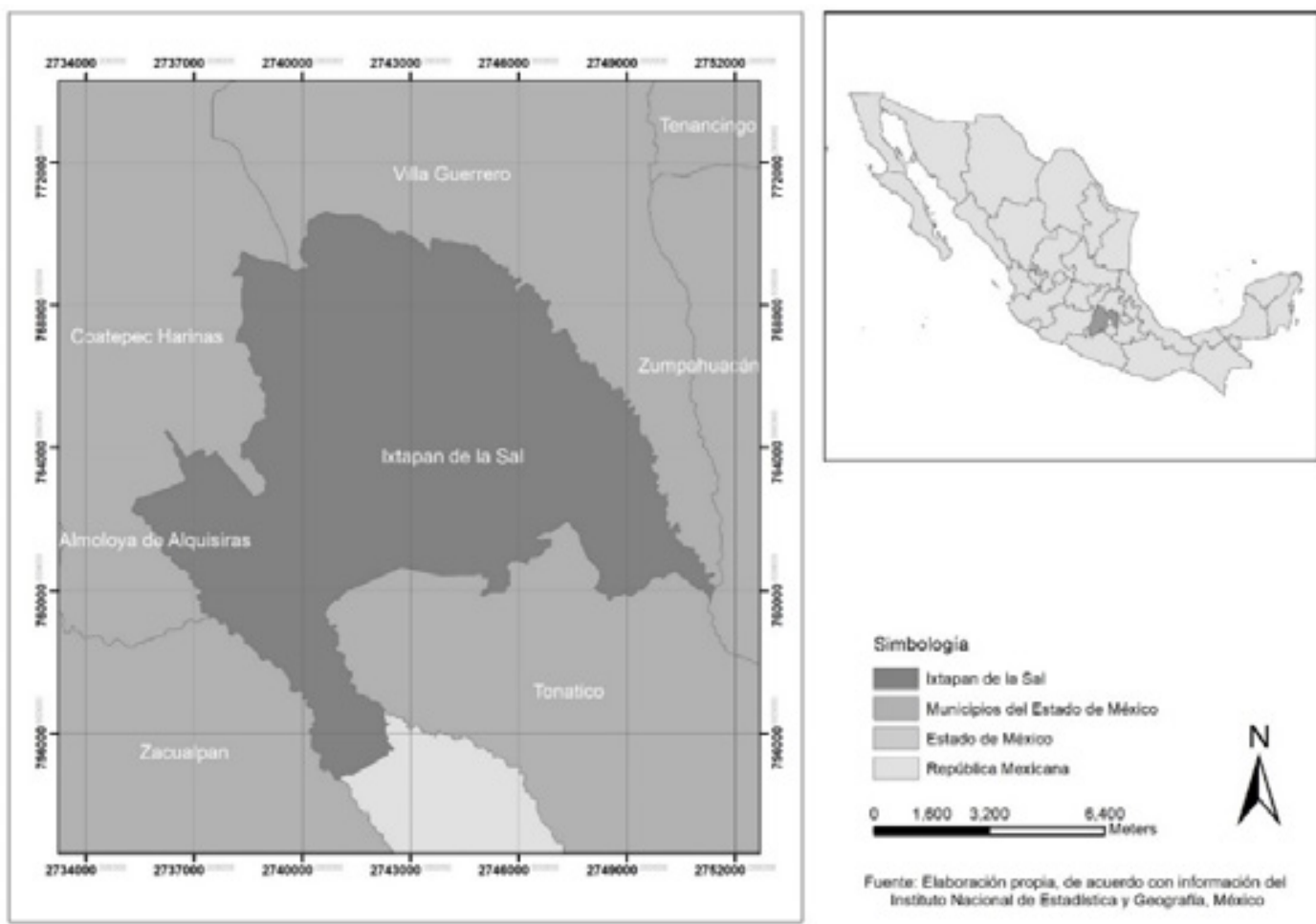

Fuente: elaboración propia, de acuerdo con información del Instituto Nacional de Estadística y Geografía (INEGI, 2019).

Otro impulso en el municipio se da en 1990 con la autorización para la construcción de conjuntos urbanos y fraccionamientos y la inauguración de la autopista Tenango del Valle-Ixtapan de la Sal, que coincide con la transformación del Balneario Ixtapan en Parque Acuático. En el 2015, Ixtapan de la Sal obtuvo la denominación de Pueblo Mágico (Gobierno del Estado de México, 2016-2018).

Entre las problemáticas presentadas en el municipio, destaca que el $49 \%$ de su población ocupada cuenta con hasta 2 salarios mínimos, tiene un grado de marginación medio, y un Índice de Desarrollo Humano de 0.72 (Gobierno del Estado de México, 2016-2018). A pesar de que el sector servicios participan con el $82 \%$ en el Producto Interno Bruto, en el 2010, el 59\% de la población ixtapense se encontraba en situación de pobreza, principalmente con falta en el acceso a la seguridad social, a la alimentación, a los servicios básicos en la vivienda y el rezago escolar (Gobierno del Estado de México, 2016-2018). La falta de servicios públicos se muestra de manera diferenciada, mientras que la ciudad Ixtapan de la Sal y Rancho San Diego tienen menos carencias, Ahuacatitlán, Llano de la Unión, entre otros, carecen de agua entubada y drenaje (Gobierno del Estado de México, 2016-2018).

\section{Metodología}

Para el análisis de los espacios de representación de los actores sociales y económicos que han intervenido en la configuración del destino turístico de Ixtapan de la Sal se ha hecho uso de la metodología cualitativa, es decir, la comprensión e interpretación de los hechos sociales mediante los significados intersubjetivos (Jorge, 2002; Ruiz, 1999). 
La implementación de técnicas del método etnográfico permitió el acercamiento a los componentes subjetivos, es decir, a lo microsocial. Por lo que, la observación y el recorrido de campo permitieron la identificación y el contacto con las personas para entrevistarlas (Tabla 2) (Delgado y Gutiérrez, 1999; Gómez Nieves, 2010).

Tabla 2: Ficha técnica de las entrevistas.

\begin{tabular}{|c|c|c|c|}
\hline Actor social & Nombre/Cantidad & Lugar: Ixtapan de la Sal & Fecha \\
\hline \multirow[t]{4}{*}{$\begin{array}{l}\text { Autoridades } \\
\text { locales }\end{array}$} & $\begin{array}{l}\text { Arquitecto Tonalli de Jesús } \\
\text { Rodríguez Fuentes }\end{array}$ & Departamento de Desarrollo Urbano & 1/junio/2018 \\
\hline & $\begin{array}{l}\text { Cronista Municipal Alejandra } \\
\text { Ayala Ayala }\end{array}$ & Presidencia Municipal & 1/junio/2018 \\
\hline & $\begin{array}{l}\text { Administrador del Balneario } \\
\text { Municipal Francisco Adolfo } \\
\text { Díaz Ayala }\end{array}$ & Balneario Municipal & 2/junio/2018 \\
\hline & $\begin{array}{l}\text { Director General de Desarrollo } \\
\text { Económico y Turismo Juan } \\
\text { Carlos Acacio Abarca }\end{array}$ & Balneario Municipal & 14/junio/2018 \\
\hline $\begin{array}{l}\text { Empresarios/ } \\
\text { Gerentes }\end{array}$ & 11 entrevistas & Lugares de trabajo & $\begin{array}{l}\text { 14/junio/2018-4 } \\
\text { septiembre } 2018\end{array}$ \\
\hline $\begin{array}{l}\text { Población } \\
\text { local }\end{array}$ & 17 entrevistas & $\begin{array}{l}\text { Jardín Central, comercios, espacios } \\
\text { de trabajo, Iglesia, y avenidas } \\
\text { principales. }\end{array}$ & $\begin{array}{l}\text { 24/junio/2018-20/ } \\
\text { octubre/2018 }\end{array}$ \\
\hline Turistas & 22 entrevistas & $\begin{array}{l}\text { Jardín Central, lugares de trabajo y } \\
\text { casas particulares. }\end{array}$ & $\begin{array}{l}\text { 16/junio/2018-6/ } \\
\text { noviembre /2018 }\end{array}$ \\
\hline
\end{tabular}

Fuente: elaboración propia, de acuerdo con información del trabajo de campo (2018).

Se hizo uso del análisis del discurso de las entrevistas semi-estructuradas, lo que permitió una interpretación significativa de las representaciones sociales personalizadas mediante la intencionalidad y el contexto de las experiencias de los actores involucrados (Delgado y Gutiérrez, 1999). De lo anterior, se desprende la perspectiva emic, que remite a "la significatividad y el sentido para el actor" (Delgado y Gutiérrez, 1999:152). Mientras que lo etic se refiere a "la significatividad y el sentido para el observador" (Delgado y Gutiérrez, 1999: 152).

Además de la riqueza obtenida de las entrevistas y su análisis, la consulta de información oficial de Planes de Desarrollo y Agendas de Competitividad, hicieron posible el uso de la triangulación de datos (Valles, 1999).

Para el análisis de los resultados, éstos se han divido en tres, de acuerdo con los conceptos de lugar, entre-lugar y no lugar, cruzándolos con las variables de análisis de los espacios de representación de Harvey (1990), mismos que se muestran a continuación.

\section{Los espacios de representación en el Pueblo Mágico de Ixtapan de la Sal, México}

\subsection{El lugar}

Ixtapan de la Sal es un lugar en el que sus pobladores locales se reconocen entre ellos, organizan sus festividades cívicas y religiosas que celebran en los sitios destinados para ello, además, son conscientes de la riqueza natural que les ha permitido ser un destino turístico. Sin embargo, ante la apropiación, uso, dominio y control de los recursos naturales y culturales por parte de agentes políticos y económicos han surgido los imaginarios de desposesión, nostalgia y falta de control en la toma de decisiones ante las transformaciones que ha sufrido el destino, por lo tanto, marcando una delgada línea entre un lugar y un entre-lugar. Es decir, el destino ha sido fragmentado tanto material como simbólicamente, dando lugar a un espacio compartido con otros actores para fines diversos (Figura 2). 
La población local es consciente de que la principal atracción turística es el agua termal, sin embargo, el uso y la explotación no está en sus manos, por lo que genera un sentimiento de desposesión. De los 10 manantiales de agua termal existentes en Ixtapan de la Sal; el "Ojito" y "Baños San Gaspar" alimentan el Balneario Ixtapan, mientras que el "Bañito" y de "la Cruz" son explotados por el Balneario Municipal, además, otro está bajo el control del Magisterio, hay otro en la casa de Salvador Sánchez Colín, y uno en Ollin Calli (Poblador local 7, 2018).

Durante la industrialización y el Estado Benefactor, el gobierno estatal construyó vías de comunicación para reducir los tiempos de traslado a este destino, además, el Balneario Ixtapan dejó de ser un lugar abierto para convertirse en un lugar de espectáculo o entre-lugar, que bajo la administración del Sr. San Román (1939) llegaron turistas nacionales y extranjeros, convirtiendo a Ixtapan de la Sal en un destino turístico de salud, por ende, dejando de ser solo un pueblo agrícola. Para la población tal explotación significó remuneración económica tanto por los turistas como por el Sr. San Román (empleo, modernización del municipio, pases para entrar al balneario, acceso a la seguridad social), al grado que se le considera como una época de bonanza que quieren recuperar. De manera que, el Balneario Ixtapan si bien era explotado por un agente externo, no se le consideraba ajeno al municipio dadas las cualidades que derramaba en la población.

Figura 2: El lugar.
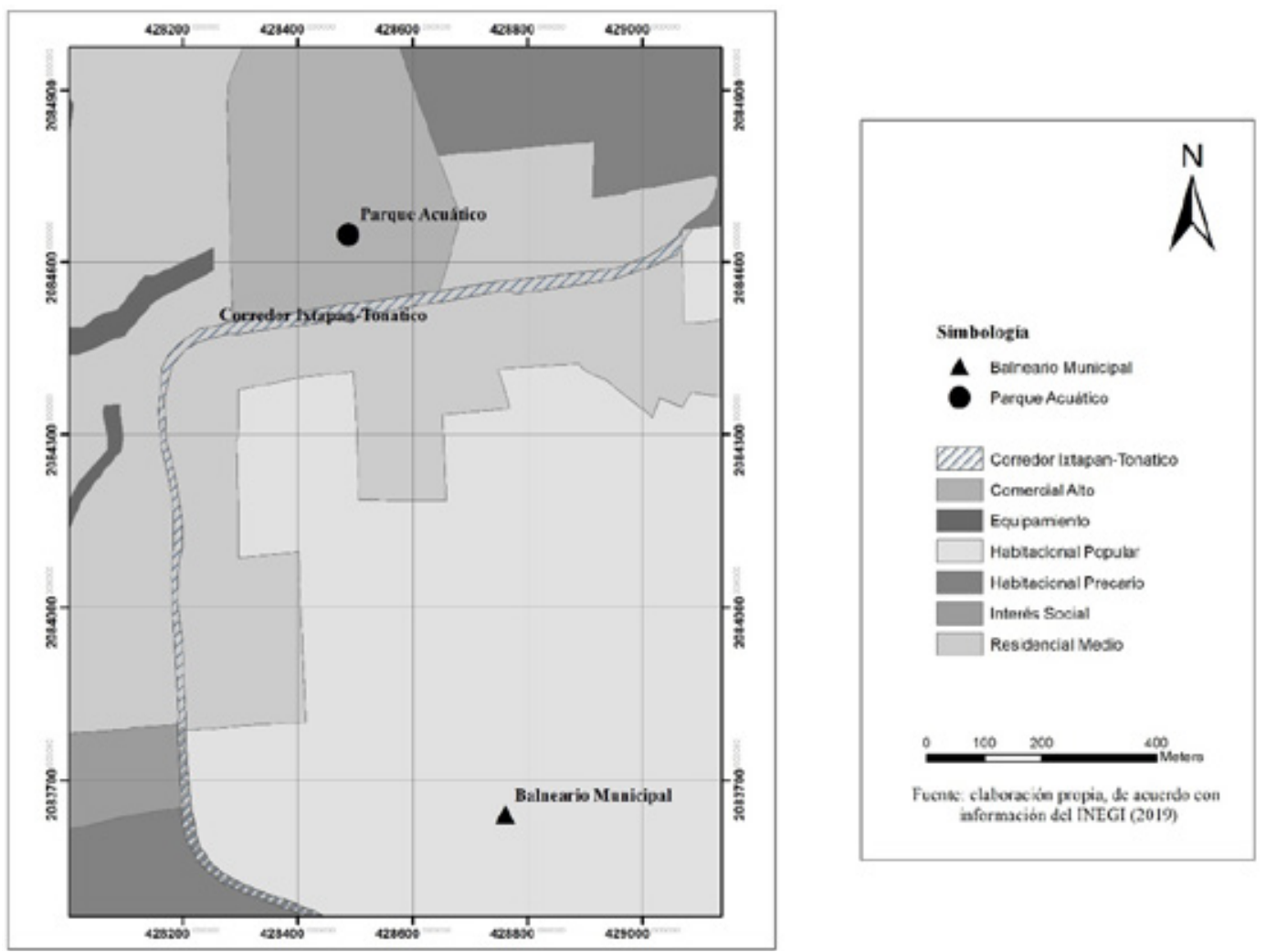

Fuente: elaboración propia, de acuerdo con información del INEGI (2019).

De hecho, la población local y algunos empresarios tienen la idea de que la llegada de turistas extranjeros ha disminuido, por lo que esperan que Ixtapan de la Sal resurja como ese destino de interior que fue por excelencia.

La explotación de las aguas termales del "Ojito" y "San Gaspar" continúan en la tercera generación de la familia San Román bajo el nombre de Parque Acuático (década de 1990), situación atribuida a las relaciones políticas, lo que resulta injusto para los nativos: 
“...no es justo que él haya o tenga o sus descendientes conserven un volumen de agua mayor que la población...empezó a abarcar mucho en terrenos, en servicios, el agua, y también lo que es el bajo sueldo de los empleados...está muy bien relacionado políticamente.” (Poblador local 7, 2018).

La desaparición del Balneario Ixtapan se da en el contexto del neoliberalismo, que se caracteriza por la precarización laboral y la escenificación del espacio, produciendo desterritorialización para la población y reterritorialización para los turistas tanto material como simbólica.

Con la aparición del Parque Acuático se da un cambio en los imaginarios de la población, que, al no ser una opción de trabajo, surge la representación mental de desposesión y acaparador de turistas. Sin embargo, el Parque Acuático es un entre-lugar debido a que los pobladores tienen recuerdos de tal espacio, ya sea por cuestiones laborales o familiares. Quienes afirmar visitarlo es bajo determinadas condiciones, es decir, en vacaciones, por lo que se consideran turistas, quienes no lo visitan es por cuestiones económicas, convirtiéndose en una barrera simbólica.

Ixtapan de la Sal es un destino que se relaciona con el agua, el clima, la naturaleza, lo rural, etc., así como oportunidad de trabajo, imaginarios que sirvieron para atraer turistas residenciales y a migrantes; los primeros colocándose en espacios estratégicos, por ejemplo, cerca del Parque Acuático (en la Figura 2 está representado por el uso de suelo comercial alto), los segundos, en los límites del municipio y la población local en medio (en la Figura 2 se observa el uso de suelo habitacional popular, precario e interés social). Lo anterior, permitió que se fragmentara el espacio de acuerdo con la condición social, fungiendo como una manera de identificación y de diferenciación:

“...[del] boulevard para abajo es otro ambiente, otra clase de gente, más humilde, muchachos...ya marcados... [en] los baldíos están construcciones bonitas, gente de dinero ha venido a vivir acá...hasta el Presidente Peña Nieto vive acá arriba..." (Poblador local 11, 2018).

También, ha producido cambios en su entorno. Con la construcción de casas se ha dado la nostalgia por el paisaje anterior, la extrañeza por épocas donde el municipio y sus calles tranquilas eran suyas: "Todo era hermoso... antes no había como ahora paredes que cierran con alambre de púas, con electricidad... ahora puras casas y casas." (Pobladora local 9, 2018). De hecho, señalan que la pérdida de tranquilidad se ha dado debido a la llegada de gente.

Además, se ha dado lugar a otros problemas, por ejemplo, las concernientes al agua y el suelo: “...[el] abasto, pero también es de costo... el agua en Ixtapan es cara...el valor de la tierra ha incrementado porque el destino se ha modernizado..." (Empresario, 2018). La población local ya no es dueña de todos los negocios, hay más ruido de coches y tránsito, hay un incremento de bares, principalmente en la calle Juárez, donde se concentran los hoteles, perjudicando tanto a huéspedes como a la población local.

Respecto a las fiestas cívicas, principalmente el grito de Independencia (15-16 de septiembre), que, si bien es un símbolo de identidad, de relación entre turistas y la población local, éstos últimos la valoran de manera diferenciada. Hay gente que ve tal celebración como una oportunidad para obtener ingresos, por ende, se valora de manera positiva, sin embargo, para otros ya no tiene esa carga identitaria dado que se transformado, incluso han dejado de acudir debido a los conflictos que se suscitan (peleas callejeras, jóvenes intoxicados, accidentes provocados por aventar objetos o por el uso y quema de mosquetes), por lo cual surge el sentimiento de nostalgia al recordar cómo se celebraba anteriormente "antes era muy bonito, lo del 15-16 de septiembre...no había borrachitos" (Pobladora local 9, 2018).

Tal nostalgia también se remite a la época en que Ixtapan de la Sal era un pueblo agrícola, donde era “...tranquilo todo... estaba muy chico... antes era pura tierra todo, mucho árbol, mucha vegetación... se acabó todo eso...no había restaurantes internacionales..." (poblador local 11, 2018). Es decir, es el recuerdo por un pasado en el que vivían y disfrutaban de su pueblo, dado no era usado ni apropiado por agentes externos.

Los Pobladores locales expresan pérdida de la tranquilidad, pues en el presente se vive con inseguridad, situación relacionada con al asesinato del entonces Presidente Municipal en el 2008, y precisan a esa década como el inicio de la intranquilidad, aunque para la población local la principal causa es que “... tanta gente que se está viniendo...de fuera...más inseguro...” (Poblador local 12, 2018). Sin embargo, los inmigrantes son tanto por cuestiones laborales como turísticas, de éstos últimos, los nativos identifican tanto al turismo sano como al turismo delincuente: “...viene el americano y deja su dinero...propinas... era el beneficio...Imagínese que vienen delincuentes...” (Poblador local 17, 2018). 
Otro de los imaginarios de la población es el hecho de que no intervienen en la toma de decisiones, dado que sugieren la existencia de "caciques" que no solo explotan los recursos naturales y a la población, sino que inciden en las políticas municipales de acuerdo con sus intereses "...es costumbre como los que tienen dinero han atado a la gente para que no diga nada, para que siga[n] siendo esclavo[s]." (Poblador local 13, 2018). Lo anterior, ha impedido la llegada de otras opciones laborales.

Hay otros espacios representativos para la población, sin embargo, considerando que Ixtapan de la Sal es un destino turístico, son lugares que comparten tanto los locales como los foráneos, de manera que se consideran entre-lugares, mismos que a continuación se explican.

\subsection{Los entre-Lugares}

Ixtapan de la Sal es un destino turístico, debido al impulso que se le dio al Balneario Ixtapan en la etapa de la industrialización y el Estado Benefactor al promocionar las propiedades curativas de las aguas termales, mismas que se quedaron en el imaginario de los turistas "...destaca Ixtapan por ser un lugar donde están las aguas termales, que sí sirven para algunas terapias en el cuerpo.” (Turista 9, 2018). El Balneario Ixtapan posteriormente se convirtió en Parque Acuático, que junto con el Balneario Municipal son los espacios de ritual construidos. Lo anterior, de acuerdo con las principales actividades que realizan los turistas: visitar balnearios. De manera que se incluye el análisis de entre-lugares al Balneario Municipal, el Parque Acuático y el jardín central, siendo lugares tanto públicos como privados que comparten la población local y flotante (Figura 3).

\subsubsection{Balneario Municipal}

Como parte del impulso a la modernización y diversificación al turismo de la localidad, las autoridades construyeron el Balneario Municipal donde anteriormente se encontraban los manantiales "El Bañito" y "la Cruz", a los que accedían tanto la población local como eventuales viajeros. Los primeros accedían

\section{Figura 3: Los entre-lugares.}
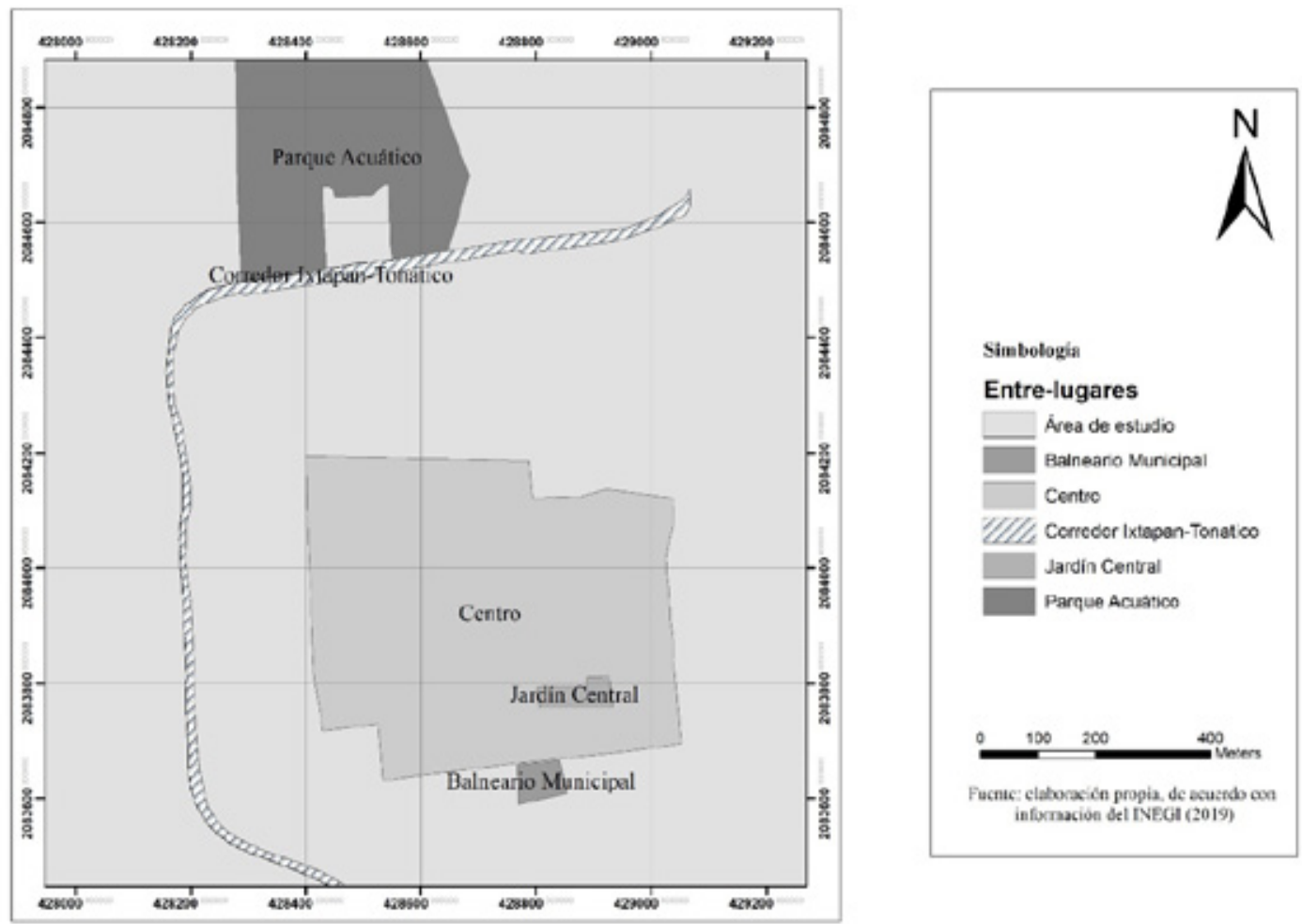

Fuente: elaboración propia, de acuerdo con información del INEGI (2019). 
de manera gratuita, actualmente ya no acuden debido al trabajo, falta de tiempo, etc., sin embargo, forma parte del imaginario espacial debido a que se encuentra cerca del Centro Histórico (pueblo), es administrado por las autoridades municipales y es un entre-lugar de recuerdos. También se le considera como un espacio de ritual construido, dado que los turistas a partir de 40 años son los que más lo visitan, porque funge como un entre-lugar para el descanso, la recreación, la convivencia familiar, medio de socialización, la recuperación de salud a través de la relajación, de retorno a lo rural y que apela a la nostalgia, es decir, han visitado a Ixtapan de la Sal por décadas y por generaciones.

\subsubsection{Parque Acuático}

En el contexto del neoliberalismo, hace su aparición, por lo que surgieron otros imaginarios tanto en los turistas como en la población. Para los turistas dejó de ser un destino turístico de salud, para convertirse en uno recreativo, de descanso y de convivencia, especialmente para familias jóvenes (de 31 a 40 años) con determinado poder adquisitivo. Por lo tanto, se le considera como un espacio de ritual construido que se inserta en el imaginario como un entre-lugar de recreación. Para la población local es un lugar lejano, tanto espacial como simbólicamente. El Parque Acuático se ubica en el boulevard Ixtapan de la Sal-Tonatico, por lo que es accesible para los turistas, mientras que los pobladores lo diferencian del pueblo (formar parte del municipio, pero no del Centro Histórico de la Ciudad). También se le considera como competencia comercial que acapara a los turistas, y que las autoridades promocionan "...únicamente al Parque Acuático...den publicidad a Ixtapan de la Sal, a la Iglesia, al mercado municipal, a las artesanías locales, aquí...” (Pobladora local 8, 2018). Para la población local también es un lugar caro, pero que ha generado nostalgia debido a que anteriormente lo visitaban por medio de pases, actualmente acuden a este sitio en vacaciones, convirtiéndolos en turistas en su propio espacio.

\subsubsection{Jardín Central}

Es el espacio abierto que comparten tanto pobladores locales como turistas, pero cada uno le refiere de distinta manera: “...el centro...nosotros le decimos el jardín, y el turismo le dice el parque...el atractivo del centro las paletas, la nieve...casi los domingos...” (Poblador local 12, 2018).

Forma parte del recorrido de los turistas por Ixtapan de la Sal, dado que les permite comprar productos de la región, estar en contacto con los ixtapenses, tomar fotografías del monumento a los Mártires de Ixtapan, observar las celebraciones locales, etc., es decir, disfrutar lo que pertenece al pueblo, aunque otros visitantes mencionan que el principal imaginario del lugar turístico son las aguas termales, por lo que no siempre visitan el jardín, cuestión que para los pobladores locales se relaciona con la poca promoción del pueblo de Ixtapan de la Sal.

Si bien es un lugar propiamente dicho para la población, ha sido sujeto a la posesión e intervención de la aplicación del reglamento de Pueblos Mágicos (2015) por parte del gobierno municipal, con el fin de hacerlo más atractivo para que se inserte en la memoria de los turistas, y se convierta en un espacio de ritual construido que expanda la oferta turística (descentralizador del poder económico que tiene el Parque Acuático). Ejemplo de lo anterior, son las remodelaciones físicas de las fachadas del primer cuadro del Centro Histórico que han dado lugar a mitologías del lugar para explicar la riqueza de determinados "caciques". Los "caciques" son personas que tienen a su posesión lugares estratégicos que también son objeto de deseo, debido a que permiten la derrama económica, y la especulación del suelo.

Por otra parte, ante tales intervenciones, el jardín central es un espacio de incertidumbre para los vendedores ambulantes, de despojo y no familiaridad para la celebración de festividades cívicas y culturales. Para las autoridades implica la aplicación del reglamento de Pueblos Mágicos, el control en el acceso de sustancias tóxicas y recuperación de la participación simbólica, de lo contrario pueden perder la denominación Pueblo Mágico, la inversión pública y privada, y la atracción de turistas. Tales esfuerzos comienzan, pero para los turistas le falta exponer lo tradicional para que se convierta en un referente del destino.

La población local concibe a Ixtapan de la Sal como un todo, de manera que al primer cuadro del Centro Histórico de la Ciudad de Ixtapan de la Sal se le considere Pueblo Mágico les ha causado confusión: "Es un pueblo, es una ciudad..." (Poblador local 2, 2018). Además, no ven un incremento en la afluencia de turistas ni en la seguridad, pero si cortes de agua, de luz y del piso, por lo que lo denominan un pueblo trágico. Las autoridades tienen el imaginario de hacer del Pueblo Mágico de Ixtapan de la Sal un "San Miguel Allende", es decir, un destino turístico para jubilados extranjeros, por su parte, algunos empresarios tienen la idea de la creación de "experiencias" para diversificar la oferta ante la estacionalidad turística, los ixtapenses creen que el municipio no va a crecer en la 
oferta laboral dado el control territorial y político. Sin duda, la intervención de determinados actores sociales puede permitir o limitar el crecimiento económico y social de Ixtapan de la Sal de acuerdo con sus intereses.

\subsubsection{Pueblo Mágico}

Como parte de la globalización, en la que se pretende la inserción de zonas alejadas a la economía del mercado de servicios, y con ello, fragmentando y reduciendo el espacio para insertarlo en dicha economía del mercado, a Ixtapan de la Sal se le concedió la denominación de Pueblo Mágico, cuya pretensión es la participación de diferentes actores sociales tanto en la planificación como ejecución de proyectos económicos y sustentables que impulsen al destino turístico.

Además, el fin de tal denominación es atraer turistas, dado que tanto para empresarios locales y foráneos como para la población local implican fuentes de trabajo e ingresos, al grado que se denota una dependencia económica, por ende, ocasionalmente pueden expresar incomodidad ante su presencia. Sin embargo, son las familias a las que se les valora de mejora manera por encima de los jóvenes: "...son familiares que le daban más estabilidad a los hoteleros...la juventud te provoca problema..." (Empleado 2, 2018). Cuentan con dos tipos de perfiles de turistas: los que llegan al hotel y no salen al pueblo, y los que llegan al Parque Acuático y salen al pueblo y compran. Siendo éstos últimos, los catalogados como turistas con expectativas altas, y “...perfil bajo...pues viene al balneario que busca el descuento..." (Empresario 3, 2018). Para la población, el turista es visto como el generador de la derrama económica directa o indirectamente, debido a la creación de comercios que abastecen de productos y de empleo, así como de la construcción de casas para turistas residenciales, ideas que se refuerzan por las autoridades.

Entonces, para los empresarios y autoridades la idea es consolidar a Ixtapan de la Sal como un Pueblo Mágico, por ende, deben diversificar la oferta turística mediante experiencias que incluyan y exploten lo cultural y lo ecológico del destino. Por ejemplo, las autoridades tienen el imaginario de hacer de Ixtapan de la Sal un destino de retiro para extranjeros, o bien, implementar otros tipos de turismo (de bodas, homosexual, ecoturismo). Sin embargo, el crecimiento, las posibles inversiones y la oferta turística se verán limitados por aquellas personas que tienen el poder político y económico “...mi jefe y su hermano no van a vender...tanto Rancho San Diego, como Marriott, tampoco lo van a hacer, y ya no quedan más terrenos para una infraestructura, un hotel grande..." (Empleado 6, 2018).

Sin embargo, la población local se proyecta sobre condiciones vulnerables y con desigualdades sociales: “...sin menos gente... por el narcotráfico, la inseguridad...no tenemos una buena policía...el rico más rico, el pobre más pobre, y los que somos de clase media, de clase media...” (Pobladora local 4, 2018). La disminución del turismo, para la población local, se debe a que identifican a Ixtapan de la Sal como un destino caro, además, de la competencia con otros destinos más accesibles. Los turistas manifiestan que para ser Pueblo Mágico le falta exposición de lo tradicional, además de que ubican al Centro Histórico como una ciudad, con determinados problemas (presencia de personas en situación de calle, intoxicados y prostitución, falta de mantenimiento y de eventos culturales y recreativos).

\subsection{Los no lugares}

Esta categoría de análisis geográfico se analizan dos vías de acceso impulsadas por el gobierno federal, además, de los hoteles y una plaza comercial, mismos que forman parte del destino turístico y que se han ido construyendo desde el Estado Benefactor hasta la globalización (Figura 4).

\subsubsection{Las vialidades}

La Carretera Federal N. 55 Toluca-Ixtapan instauró el imaginario de reductor de distancia y tiempos tanto para las autoridades, la población local y los turistas. A estos últimos, el recorrido les permitió reconocer a otros pueblos aledaños a Ixtapan de la Sal y su cultura, por lo que se incorporó la imagen mental de provincia y de vegetación (cuestión ilustrativa y panorámica). Para la población significó reducción en tiempos de traslado a la Ciudad de México y a Toluca, sin embargo, para no pagar las casetas utilizan vías alternas. Actualmente, la autopista de cuota Tenango-Ixtapan de la Sal es concebida por las autoridades municipales como un reductor de tiempo y espacio que va a permitir la afluencia continúa de turistas. Para los turistas implica cercanía, rapidez, seguridad y comodidad, pero acortando los tiempos de estancia en el destino turístico, mientras que el costo de las casetas ha convertido que el viaje a Ixtapan de la Sal sea prohibitivo. 


\subsubsection{Los hoteles}

Para la población local y las autoridades fungieron como una "escuela" y como el reflejo de las transformaciones que ha tenido el destino. Los hoteles durante la etapa de la industrialización fueron espacios laborales en los que aprendían el oficio de meseros, recamaristas, etc., obtenían capacitación y seguridad social, por lo tanto, solían ser leales a la empresa, aunque la remuneración fuera baja, misma que se compensaba con las propinas (dólares). Como reflejo de las transformaciones físicas del destino, dado que rememoran la ubicación de los primeros hoteles, los dueños, los cambios de giro y arquitectónicos que han tenido a lo largo del tiempo. En la actualidad y como consecuencia del modelo neoliberal, los hoteles son una de las diferentes opciones laborales que hay en Ixtapan de la Sal, donde se manifiesta la rotación de empleo y la pérdida de la seguridad social. Son parte del paisaje, los visitan por cuestiones laborales, pero se valora vivir cerca de ellos, dado el acceso a servicios públicos. Aunque, para algunos pobladores forman parte de sus experiencias. La población local los identifica como espacios caros, y segmentados; los cosmopolitas (Marriott, Hotel Ixtapan y Rancho San Diego) y los que se quedaron en los años sesenta, conformando un paisaje contradictorio en el que se refleja la globalización, por ende, la relación local-global.

\section{Figura 4: No lugares.}

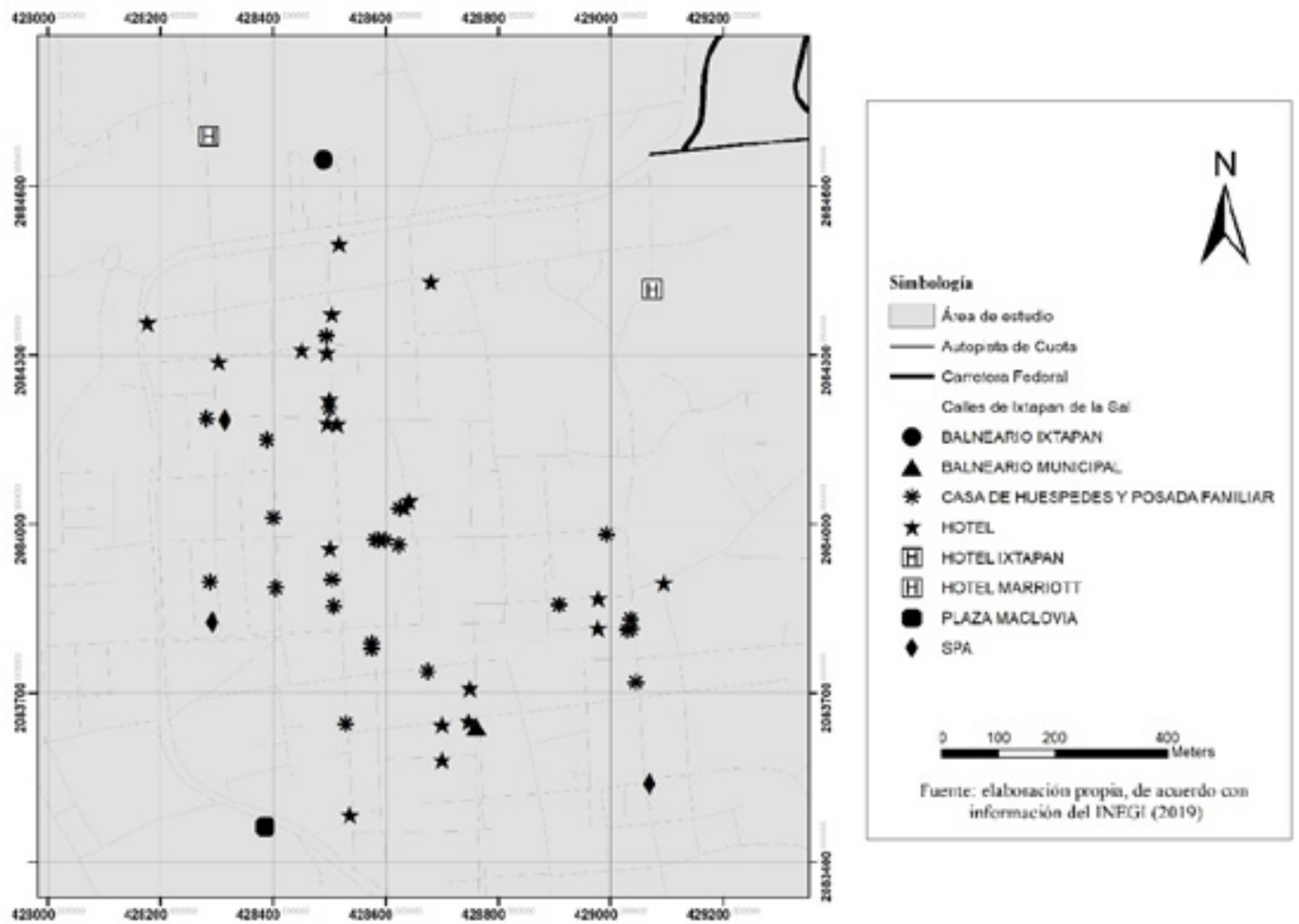

Fuente: elaboración propia, de acuerdo con información de INEGI (2019).

Para los turistas, anteriormente las casas de huéspedes y los hoteles sencillos fungían como espacios familiares y cálidos, dada la relación entre ellos y los dueños, además, su costo era más accesible. En la actualidad, impera la relación cliente-prestador de servicio, aunque hay casos de compadrazgo, de amistad y de socios. De igual manera que los ixtapenses, identifican dos tipos de servicios: los de cadena y los locales. En los primeros se denota la capacitación, la atención, la modernidad, y son destinados para un mercado con poder adquisitivo; los segundos se identifican por su falta de capacitación y de modernidad en sus instalaciones, además, son caros y destinados a un mercado con nivel medio y medio-bajo. 
Para los empresarios refieren a la "época dorada" de Ixtapan de la Sal, y se denota como un patrimonio económico y sentimental. Lo económico, porque permiten el desarrollo profesional y laboral, aunque impera la rotación de empleo, a su parecer debido a la falta de compromiso de la población y la estacionalidad del destino. Lo emocional es significativo para el cambio generacional que ha heredado las casas de huéspedes u hoteles de sus padres, y con ello, dando pauta a la relación cliente-colaborador. También, se ha convertido en un ámbito de competitividad, dada la llegada de empresas "grandes" (Marriott, Rancho San Diego), aunque cada uno tiene su clientela.

\subsubsection{Plaza comercial y spas}

Los empresarios, los pobladores locales y los turistas refieren solo a Plaza Maclovia como un espacio que recorren en familia, sin embargo, no consumen sus productos por considerarlos caros. Respecto a los spas, la población local supone que son cómodos y seguros, es decir, saben de su oferta, pero no acceden a ellos. Para los turistas son espacios a los que acuden para relajarse, incluso llegan a ubicar a algunas masajistas, pero prevalece una relación contractual. Tanto para las autoridades locales como empresarios forma parte de la oferta turística de Ixtapan de la Sal.

\section{Conclusiones}

El análisis de los imaginarios de los diferentes actores sociales que producen, consumen y viven el destino turístico de Ixtapan de la Sal nos ha permitido identificar por medio de sus experiencias, como la fragmentación física y simbólica ha influido en sus relaciones sociales y de los sujetos con el espacio.

Las categorías de análisis geográfico lugar, no lugar y entre lugar permitieron el contraste de los imaginarios de los diferentes actores sociales de Ixtapan de la Sal. Para los turistas es un destino relacionado con las aguas termales, el clima, la salud, la recreación, lo rural y la tranquilidad, para los migrantes es una fuente de trabajo, sin embargo, para la población ha implicado la fragmentación física y simbólica de su lugar, lo que ha propiciado la nostalgia por el paisaje anterior ante la invasión y desposesión de sus recursos naturales (agua, suelo) y económicos (pérdida de la posesión de negocios), de sus calles y su tranquilidad (inseguridad, ruido, tránsito).

Por su parte, las autoridades y actores económicos han impulsado el destino turístico mediante la creación de entre-lugares que en algunos casos se han convertido en espacios de ritual construidos como el Balneario Municipal, el Parque Acuático, mientras que el jardín central y el Pueblo Mágico han sido concebidos como formas de ampliar la oferta turística. Cada entre-lugar ha impactado en los imaginarios de los turistas y visitantes. Tanto al Balneario Municipal como al Parque Acuático se les ubica como espacios de atracción turística y derrama económica, sin embargo, para la población el primero es cercano y fomenta la nostalgia, mientras que el segundo es lejano, implica competencia económica, y funge como un acaparador de turistas, de desposesión y, también de recuerdos. Para los turistas refiere descanso y recreación familiar. Mientras que los empresarios valoran la ubicación.

Para la población local, el jardín central es un entre-lugar debido a las intervenciones gubernamentales para atraer turistas e inversiones bajo la denominación de Pueblo Mágico. El imaginario local es variado de acuerdo con los intereses de los habitantes y van desde el señalamiento de caciques hasta el despojo del espacio central para la celebración de festividades cívicas y religiosas. Por su parte, los turistas señalan la falta de exposición de lo tradicional y mantenimiento para que se convierta en un espacio de ritual construido.

Dentro de los no lugares se identificaron: la carretera federal y la autopista de cuota, los hoteles y la plaza comercial. Hoy en día, la autopista representa para las autoridades, la población local y los turistas un reductor de distancias y tiempos, además, para los últimos, implica seguridad, comodidad y prohibición debido a los costos de las casetas. Para la población local los hoteles son una opción más de empleo, que dividen en dos: los cosmopolitas y los que se quedaron en los años sesenta, éste último punto coindice con autoridades, empresarios y turistas, y se les señala como puntos a mejorar por medio de la capacitación. Para los empresarios representa un patrimonio económico y sentimental. Todos los actores sociales refieren una plaza comercial, misma que es considerada cara, pero que se promueve como opción turística, junto con los spas, que para la población local es una oferta que no consumen.

La condición histórico-geográfica de la posmodernidad permitió la identificación y diferenciación de las actitudes y las relaciones que se establecen entre los actores sociales del destino turístico mediante las etapas del sistema capitalista. Se denota, que durante la etapa de la industrialización y el Estado Benefactor prevalecen las relaciones entre actores políticos y económicos. Los turistas mantenían una relación cercana 
y familiar con los dueños de los diferentes establecimientos, situación que se transformó ante el cambio generacional. Los costos de los servicios eran económicos, garantizándoles el acceso. Además, durante tal etapa, la población local accedía a empleos con seguridad social, mientras que, con la instauración de modelo neoliberal, hay una variedad de empleos que ante la falta de seguridad social se da pauta a la rotación de personal. Las opciones de ocio e infraestructura turística van desde las tradicionales hasta las especializadas, permitiendo la segmentación del mercado de acuerdo con el nivel socioeconómico y generando barreras simbólicas. En la etapa de la globalización se denota la fragmentación socioespacial y las contradicciones propias del capitalismo, misma que se ha incrementado ante la implementación de políticas federales.

De lo anterior, tanto las autoridades, los empresarios, los turistas y la población local coinciden en la falta de diversidad turística y laboral. Sin embargo, se denota que tal diversidad está sujeta a las decisiones de determinados personajes, además, la distribución de la riqueza se muestra desigual.

Sin duda, los actores sociales, políticos y económicos deben establecer acuerdos para la explotación eficaz y efectiva de sus recursos naturales y/o culturales y así construir un destino turístico que satisfaga las necesidades de cada uno y vuelva a ser referente turístico.

\section{Bibliografía}

Antón Clavé, S. 1998. "La urbanización turística: de la conquista del viaje a la reestructuración de la ciudad turística". Documents D’anàlisis Geogràfica, 32:17-43.

Augé, M. 1992. Los no lugares. Espacios del anonimato. Barcelona: Gedisha editorial.

Barbini, B. 2005. "Viabilidad social para el desarrollo turístico en centros urbanos bonaerenses". Aportes y Transferencias, 9(2):148-158.

Barbini, B., Roldán, N., Cacciutto, M. y Cruz, G. 2009. "Modelos de desarrollo y visiones sobre el turismo. Aportes de la teoría del capital social al paradigma alternativo". Aportes y Transferencias, 13(1):10-26.

Barrera, J. F. 2016. El Fuerte, Sinaloa como Pueblo Mágico: Representaciones Sociales del cambio urbano en el Centro Histórico de la ciudad (Tesis de Maestría). División de Ciencias Sociales. Universidad de Sonora, México. Consultado el 24 de junio 2019 en: http://www.repositorioinstitucional.uson.mx/ bitstream/handle/unison/508/barrerabarriosjosefranciscom.pdf?sequence=1\&isAllowed=y

Bertoncello, R. 2012. "Los imaginarios de espacios distantes a partir del turismo". En Lindón, Alicia y Hiernaux, Daniel (Dirs.), Geografías de lo imaginario (pp. 205-221). Barcelona-México: Anthropos-Universidad Autónoma Metropolitana (UAM).

Bringas Rábano, N.L. y Ojeda Revah, L. 2000. "El ecoturismo: ¿una nueva modalidad del turismo de masas?”. Economía, Sociedad y Territorio, II(7):373-403.

Casellas, A. 2008. "Geografía ecocrítica: el giro medio-ambientalista como eje vertebrador de una nueva territorialidad". En Diez años de cambios en el mundo, en la geografía y en las ciencias sociales, 1999-2008. X Coloquio Internacional de Geocrítica, Universidad de Barcelona, España. Consultado el 27 de junio 2019 en: http://www.ub.edu/geocrit/-xcol/68.htm

Castrogiovanni, A. C. 2007. "Lugar, no-lugar y entre -lugar. Los ángulos del espacio turístico". Estudios y Perspectivas en Turismo, 16(1):5-23.

César Dachary, A. 2015. "El turismo: un modelo de desarrollo". Revista Latino-AM Turismología, 1(1):16-26.

César Dachary y Arnaiz Burne, S.M. 2004. "Globalización y turismo. ¿Dos caras de una misma moneda?”. Estudio y Perspectivas en Turismo, 13:303-315.

Cruz Jiménez, G., Cadena-Inostroza, C. y Zizumbo-Villarreal, L. 2011. "La reconfiguración turística de Ixtapan de la Sal, México 1980-2010”. Gestión Turística (Valdivia), 6:175-206.

Delgado, M., y Gutiérrez, J. (Eds.) 1999. Métodos y técnicas cualitativas de investigación en ciencias sociales. Madrid: Síntesis.

Gintrac, C. 2013. "Las aportaciones de la geografía radical y la geografía crítica anglosajona a la teoría urbana". Urban, 6:53-61.

Gobierno del Estado de México 2016-2018. "Plan de Desarrollo Municipal”. Gaceta Municipal, 1(3): 1-451.

Gobierno Municipal 2013-2015. "Plan de Desarrollo Municipal 2013-2015”. Gaceta Municipal, 1-302.

Gómez Nieves, S. 2010. Turismo, modos de vida y cambio social. Una propuesta teórico-metodológica. Oviedo: Septem ediciones.

Harvey, D. 1990. La condición de la posmodernidad. Investigación sobre los orígenes del cambio cultural. Buenos Aires: Amorrortu editores.

Hiernaux, D. 2012. "Los imaginarios urbanos: una aproximación desde la geografía urbana y los estilos de vida”. En Lindón, Alicia y Hiernaux, Daniel (Dirs.), Geografías de lo imaginario (pp. 88-105). Barcelona-México: Anthropos-UAM. 
Hiernaux, D. y González, C. I. 2014. "Turismo y gentrificación: pistas teóricas sobre una articulación". Revista de geografía Norte Grande, (58):55-70.

Instituto Nacional de Estadística y Geografía 2019. "Marco Geoestadístico". Consultado el 20 de mayo 2019 en: https://www.inegi.org.mx/temas/mg/

Jorge, E. 2002. La investigación social y el dato complejo. Una primera aproximación. Alicante: Universidad de Alicante. Servicio de Publicaciones.

Korstanje, M. 2007. "El viaje: una crítica al concepto de "no lugares"”. Athenea Digital, 10:211-238.

Lagunas Arias, D. 2006. "El espacio del turismo". Alteridades, 16(31):119-129.

Lefebvre, H. 2013. La producción del espacio. Madrid: Capitán Swing.

Lindón, A. 2012. "¿Geografías de lo imaginario o la dimensión imaginaria de las geografías del lebenswelt?”. En Lindón, Alicia y Hiernaux, Daniel (Dirs.), Geografías de lo imaginario (pp. 66-86). Barcelona-México: Anthropos-UAM.

López, P.A. 2004. El turismo en el desarrollo sostenible (Monografía de graduación). Licenciatura en Turismo. Universidad Nacional de Mar del Plata. Consultado el 27 de mayo 2019 en: http://nulan. mdp.edu.ar/2056/1/lopez.2004.pdf

López-Guzmán, T., Pérez Gálvez, J. C., y Muñoz-Fernández, G. A. 2018. "Satisfaction, motivation, loyalty and segmentation of tourists in World Heritage cities". Pasos. Revista de Turismo y Patrimonio Cultural, 16(1):73-86.

López, L., Valverde, C., Fernández, A.M., y Figueroa, M.E. 2015. Pueblos Mágicos, Una visión interdisciplinaria. Ciudad de México: Universidad Autónoma Metropolitana (UAM) y Universidad Nacional Autónoma de México (UNAM). Vol. I

López, L., Valverde, C., y Figueroa, M.E. 2015. Pueblos Mágicos. Una visión interdisciplinaria. Ciudad de México: UAM y UNAM. Vol. I

2017. Pueblos Mágicos, Una visión interdisciplinaria. Ciudad de México: UAM y UNAM. Vol. II

2018. Pueblos Mágicos, Una visión interdisciplinaria. Ciudad de México: UAM y UNAM. Vol. III

López Santillán, A.A. y Marín Guardado, G. 2010. "Turismo, capitalismo y producción de lo exótico: una perspectiva crítica para el estudio de la mercantilización del espacio y la cultura”. Relaciones, Estudios de historia y sociedad, 31(123):219-260.

Maldonado Garay, J. 2010. "Lugar y no-lugar: una oposición cercana a la falacia. Aportes a las características conceptuales de ambas categorías de análisis del espacio geográfico". Revista Boletín de Geografía, 32:1-10.

Méndez, E. y Rodríguez, S. 2013. “"Definiendo "lo mexicano”. Una clave: persistencias del modelo urbano colonial en los "pueblos mágicos"”. Diálogos Latinoamericanos, 21:46-67.

Moscoso, F. V. 2013. "El papel de los actores territoriales en la definición y configuración de modelos de desarrollo turístico". En El turismo y los Nuevos Paradigmas Educativos. VI Simposio en Turismo, XII Jornadas Nacional de Investigación en Turismo, Universidad Nacional de La Plata, Argentina. Consultado el 24 de junio 2019 en: http://sedici.unlp.edu.ar/handle/10915/34681

Orozco Alvarado, J. y Núñez Martínez, P. 2013. "Las teorías del desarrollo: En el análisis del turismo sustentable". InterSede, 14(27):144-167.

Pérez Correa, E. y Farah Quijano, M.A. 2002. "Los modelos de desarrollo y las funciones del medio rural en Colombia". Cuadernos de Desarrollo Rural, (49):9-27.

Pinassi, A. 2015. "Espacio vivido: Análisis del concepto y vínculo con la geografía del turismo". GeoGraphos, 6(78):135-150.

Ruiz, J.I. 1999. Metodología de la investigación cualitativa. Bilbao: Universidad de Deusto.

Schenkel, E y Almeida García, F. 2015. "La política turística y la intervención del Estado. El Caso de Argentina”. Perfiles latinoamericanos, 23(46):187-221.

Secretaría de Turismo (SECTUR) 2006. "Reglas de Operación de Pueblos Mágicos". Consultado el 8 de julio $2019 \mathrm{en:} \mathrm{http://www.sectur.gob.mx/}$

Valles, M. S. 1999. Técnicas cualitativas de investigación social. reflexión metodológica y práctica profesional. Madrid: Síntesis.

Venturini, E. J. 1999. "Crónica de unos viajes posibles, de sus condiciones y de sus efectos. Turismo en el ámbito urbano-metropolitano contemporáneo”. Aportes y Transferencias, 3(2):9-26.

Recibido:

$20 / 07 / 2019$

Reenviado:

$18 / 04 / 2020$

Aceptado:

$27 / 05 / 2020$

Sometido a evaluación por pares anónimos 